\title{
Total Ionizing Dose Radiation Effects on 14 nm FinFET and SOI UTBB Technologies
}

\author{
Harold Hughes, Patrick McMarr, Michael Alles, Enxia Zhang, Charles Arutt, Bruce Doris, Derrick \\ Liu, Richard Southwick and Philip Oldiges
}

\begin{abstract}
FinFETs and SOI FinFETs and $14 \mathrm{~nm}$ SOI Ultra-Thin-Body and BOX nFETs were irradiated under bias using a $10 \mathrm{keV} X$-ray source. Irradiation resulted in significant changes in the threshold voltages of the SOI devices and large changes in the off-state current of the bulk FinFETs.
\end{abstract}

\section{INTRODUCTION}

CMOS downscaling beyond $32 \mathrm{~nm}$ is proceeding to either FinFET technology for high performance, or Ultra-ThinBody and BOX (UTBB) planar technology for low power applications. In this paper we present total ionizing dose (TID) radiation effects data for $14 \mathrm{~nm}$ UTBB and $14 \mathrm{~nm}$ bulk silicon FinFET and SOI FinFET technologies.

During the past decade channel length downscaling of partially-depleted (PD) CMOS/SOI has resulted in technology progressively less sensitive to TID effects. Commercial $32 \mathrm{~nm}$ PD CMOS/SOI nFET transistors are 300 times less TID sensitive than nFET transistors from earlier commercial $150 \mathrm{~nm}$ PD CMOS/SOI technology [1-3]. These trends are shown in Fig. 1.

As shown in Fig. 1, scaling from $32 \mathrm{~nm}$ to $14 \mathrm{~nm}$ results in an increase in TID sensitivity or a turnaround in the TID vulnerability trend. $14 \mathrm{~nm}$ bulk and SOI FinFETs and SOI UTBB FinFETs show this turnaround in the TID response. For example, the TID-induced increase in off-state current for $14 \mathrm{~nm}$ SOI FinFET technology is nearly the same as $90 \mathrm{~nm}$ PD CMOS/SOI.

In addition to reduced doping to manage short-channel effects, scaling to $14 \mathrm{~nm}$ high performance technologies requires a major change in architecture, from a planar two dimensional (2D) layout to a three dimensional (3D) FinFET

Manuscript received July 13, 2015. This work was supported by the Defense Threat Reduction Agency through MIPR HDTRA1410817 and Grants N00173-13-1-G017 and N00173-14-1-G017.

H. Hughes and P. McMarr are with the Naval Research Laboratory, Washington, DC 20375 USA, e-mail: hughes@estd.nrl.navy.mil; Patrick.McMarr.ctr@nrl.navy.mil.

M. Alles, E. Zhang and C. Arutt are with Vanderbilt University, Nashville, TN 37235 USA, e-mail: Michael.Alles@Vanderbilt.edu; Enxia.Zhang@Vanderbilt.edu; Charles.Arutt@Vanderbilt.edu.

B. Doris, D. Liu, R. Southwick and P. Oldiges are with IBM Research, Albany, NY 12203 USA, email: bdoris@us.ibm.com; derrick1@us.ibm.com; southwick@us.ibm.com; poldiges@us.ibm.com. geometry. Before this change in geometry, and due to the partially-depleted aspect of technologies prior to the $14 \mathrm{~nm}$ node, channel doping was high and resulted in reduced TID sensitivity from radiation induced charge in isolation oxides. With lower channel doping required for scaled generations of UTBB and FinFETs, radiation-induced charge trapping in dielectric spacers, shallow trench isolation oxides and the buried oxides of SOI devices can have a significant impact on threshold voltage and off-state current [4].

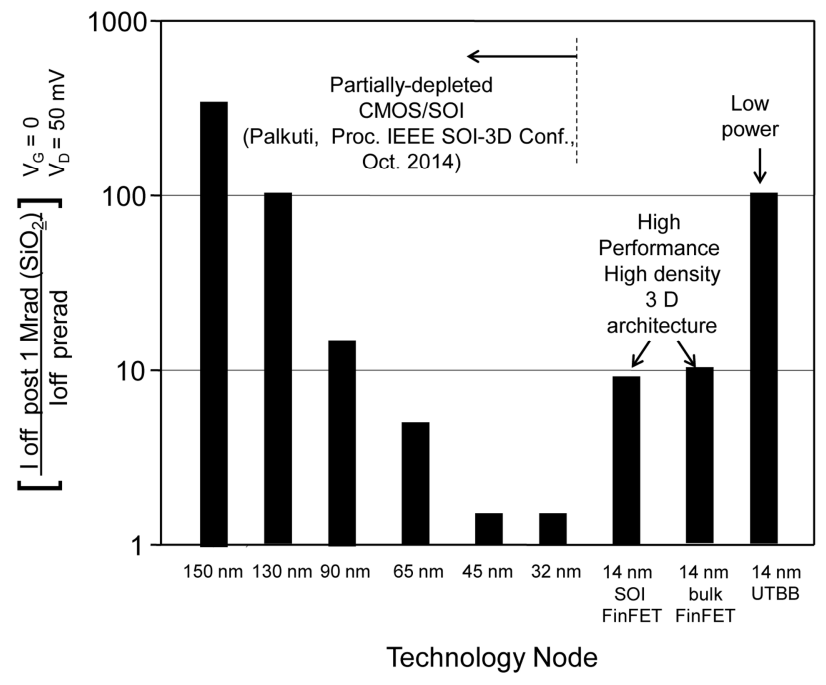

Fig. 1. Commercial Technology TID response of off-state current for a dose of $1 \mathrm{Mrad}\left(\mathrm{SiO}_{2}\right)$ versus technology scaling showing vulnerability turnaround after $32 \mathrm{~nm}$.

\section{TID RESUlts-SOI FinFETS}

$14 \mathrm{~nm}$ SOI FinFET technology was evaluated using nFETs consisting of 24 fins, each fin $50 \mathrm{~nm}$ high and $10 \mathrm{~nm}$ wide. The channel length of the FinFET was $20 \mathrm{~nm}$. These nFETs were irradiated using a $10 \mathrm{keV}$ X-ray source (ARACOR Model 4100) at a dose rate of $517 \mathrm{rad}\left(\mathrm{SiO}_{2} / \mathrm{s}\right)$ to a total dose of $1 \mathrm{Mrad}\left(\mathrm{SiO}_{2}\right)$. Three bias conditions were used; ON, OFF and pass gate (PG).

Fig. 2 shows the SOI FinFET current/voltage curves for ON bias during irradiation $\left(\mathrm{V}_{\mathrm{G}}=+0.85 \mathrm{~V}, \mathrm{~V}_{\mathrm{D}}=\mathrm{V}_{\mathrm{S}}=\mathrm{V}_{\mathrm{B}}=0\right.$ V), Fig. 3 shows the current/voltage curves for OFF bias $\left(V_{D}\right.$ 
$\left.=+0.85 \mathrm{~V}, \mathrm{~V}_{\mathrm{G}}=\mathrm{V}_{\mathrm{S}}=\mathrm{V}_{\mathrm{B}}=0 \mathrm{~V}\right)$ and Fig. 4 shows the results for $P G$ bias $\left(V_{D}=V_{S}=+0.85 \mathrm{~V}, V_{G}=V_{B}=0 \mathrm{~V}\right)$.

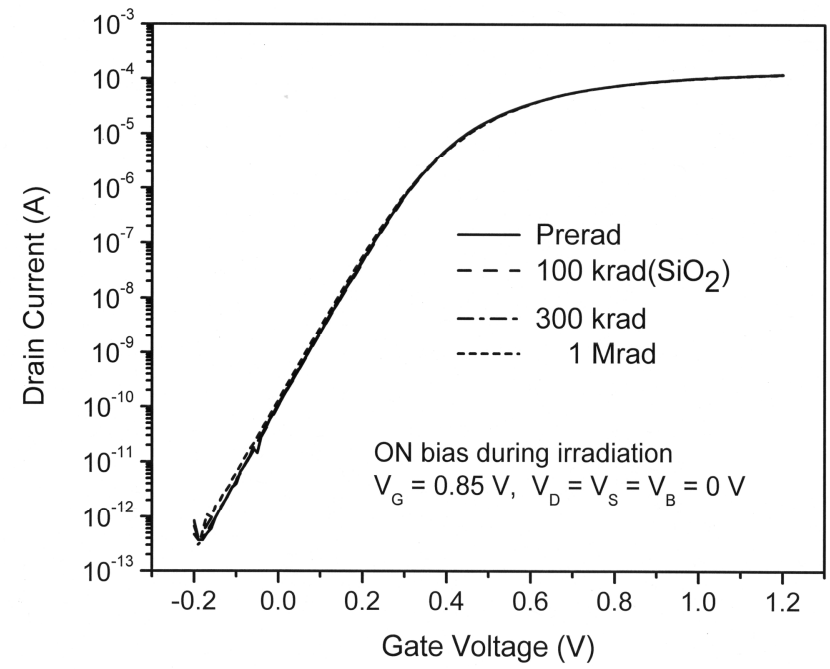

Fig. 2. Current-voltage characteristics versus $10 \mathrm{keV}$ X-ray dose $(517$ $\left.\operatorname{rad}\left(\mathrm{SiO}_{2}\right) / \mathrm{s}\right)$ for $14 \mathrm{~nm}$ SOI nFinFETs $\left(\mathrm{V}_{\mathrm{D}}=+50 \mathrm{mV}\right)$. ON bias during irradiation.

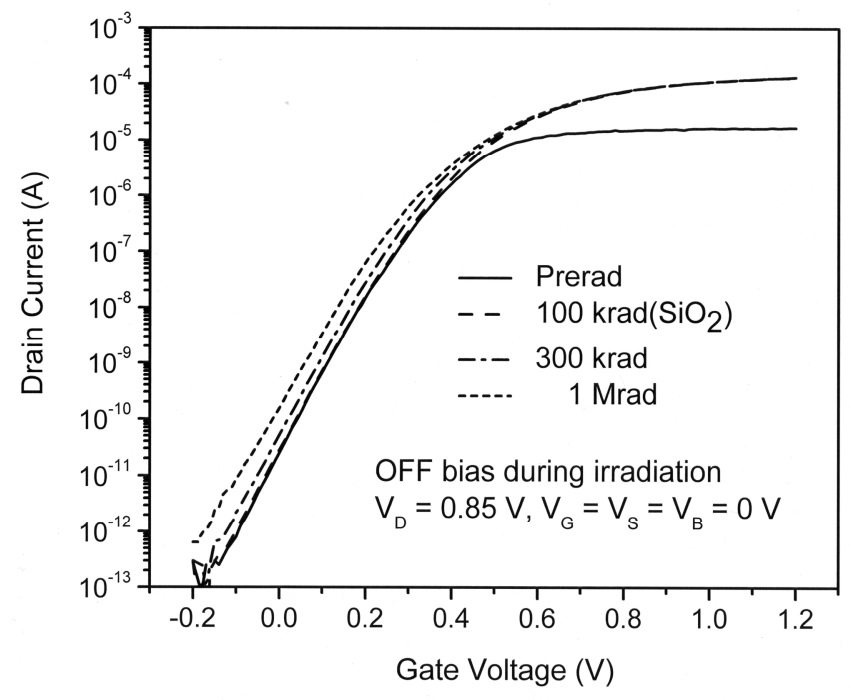

Fig. 3. Current-voltage characteristics versus $10 \mathrm{keV}$ X-ray dose (517 $\left.\operatorname{rad}\left(\mathrm{SiO}_{2}\right) / \mathrm{s}\right)$ for $14 \mathrm{~nm}$ SOI $\mathrm{nFinFETs}\left(\mathrm{V}_{\mathrm{D}}=+50 \mathrm{mV}\right)$. OFF bias during irradiation.

Fig. 5 is a summary of the threshold voltage shifts of SOI FinFETs as a function of TID in the linear region $\left(\mathrm{V}_{\mathrm{D}}=+50\right.$ $\mathrm{mV}$ ) for the three bias conditions during irradiation. Worse case is OFF bias with a threshold voltage shift of $-39 \mathrm{mV}$ at $100 \mathrm{krad}\left(\mathrm{SiO}_{2}\right),-52 \mathrm{mV}$ at $300 \mathrm{krad}\left(\mathrm{SiO}_{2}\right)$ and $-63 \mathrm{mV}$ at $1 \mathrm{Mrad}\left(\mathrm{SiO}_{2}\right)$.

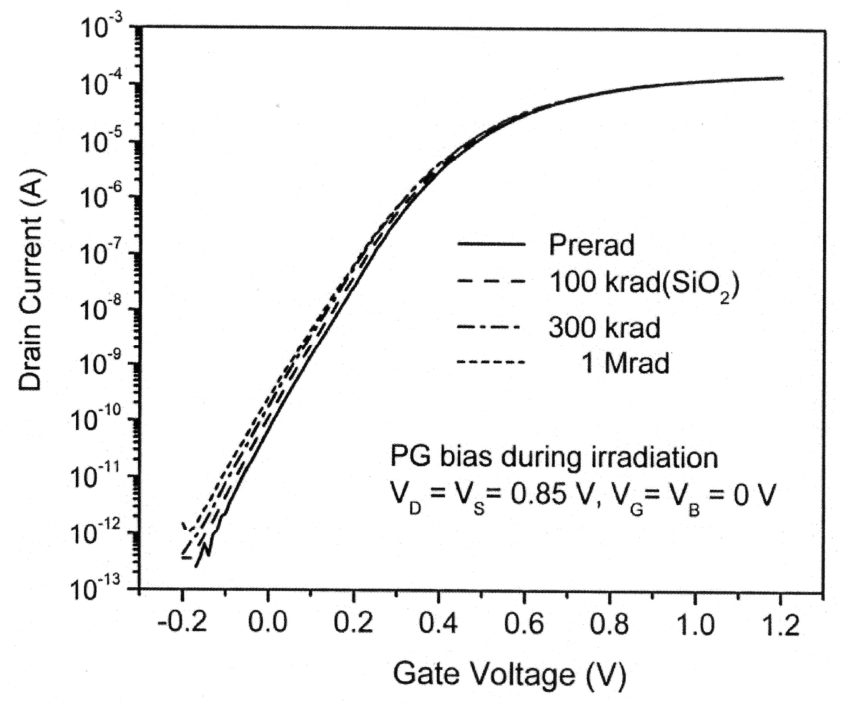

Fig. 4. Current-voltage characteristics versus $10 \mathrm{keV}$ X-ray dose $(517$ $\left.\operatorname{rad}\left(\mathrm{SiO}_{2}\right) / \mathrm{s}\right)$ for $14 \mathrm{~nm}$ SOI $n$ FinFETs $\left(\mathrm{V}_{\mathrm{D}}=+50 \mathrm{mV}\right)$. PG bias during irradiation.

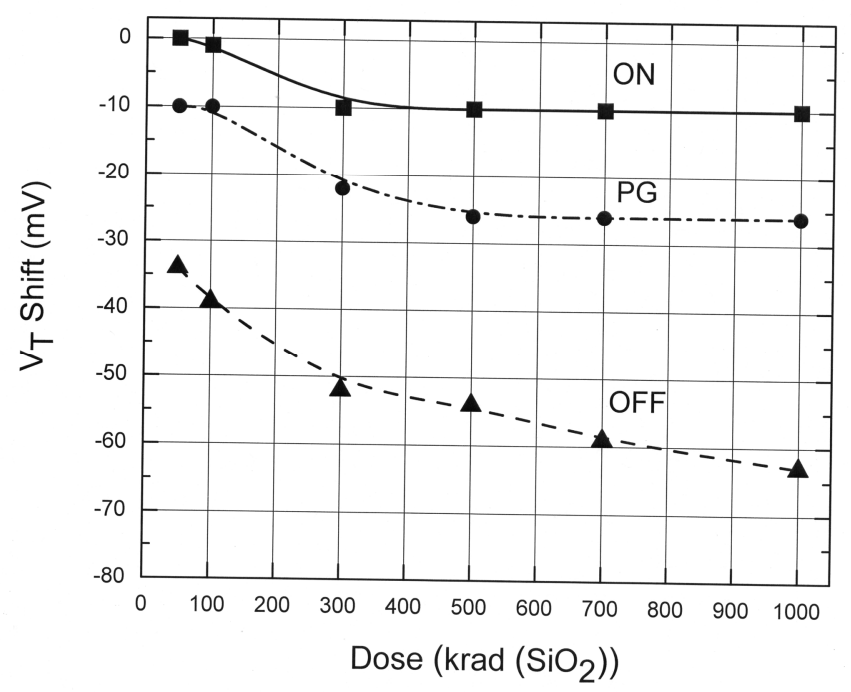

Fig. 5. Threshold voltage shifts versus $10 \mathrm{keV} \mathrm{X-ray} \mathrm{dose}\left(517 \mathrm{rad}\left(\mathrm{SiO}_{2}\right) / \mathrm{s}\right)$ for $14 \mathrm{~nm}$ SOI FinFETs biased ON, OFF and PG during irradiation. 


\section{TID Results-BUlK FinFet}

$14 \mathrm{~nm}$ bulk silicon FinFET technology was evaluated using nFETs consisting of 24 fins, each $50 \mathrm{~nm}$ high and 10 $\mathrm{nm}$ wide. The device channel length was $20 \mathrm{~nm}$. These nFETs were irradiated to a total dose of $1 \mathrm{Mrad}\left(\mathrm{SiO}_{2}\right)$ using the $10 \mathrm{keV} \mathrm{X}$-ray source. Two bias conditions were used; $\mathrm{ON}$ and OFF. Figs. 6 and Fig. 7 show the bulk silicon FinFET current/voltage curves for ON bias during irradiation in the linear $\left(\mathrm{V}_{\mathrm{D}}=+50 \mathrm{mV}\right)$ and saturation $\left(\mathrm{V}_{\mathrm{D}}=+800 \mathrm{mV}\right)$ regions. Figs. 8 and Fig. 9 show characteristic curves for OFF bias during irradiation.

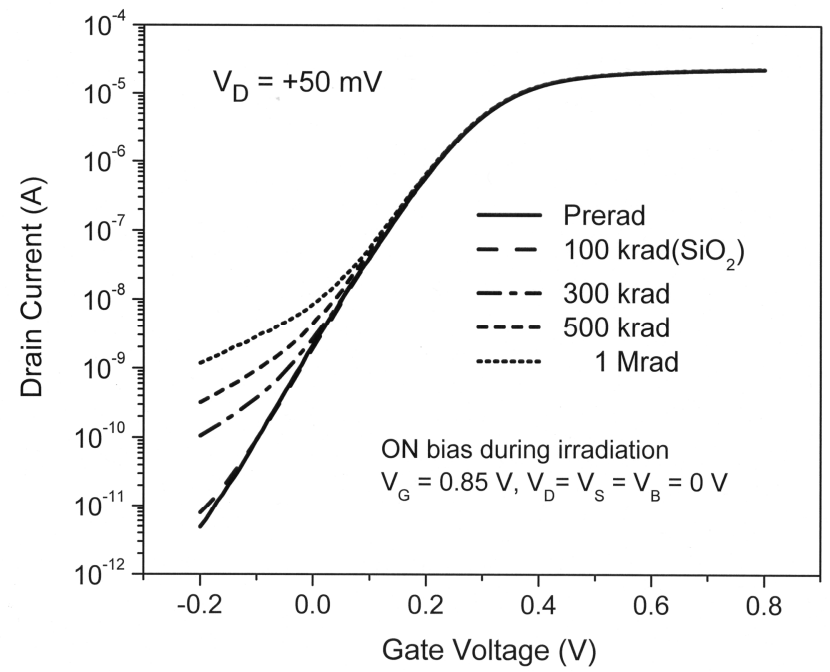

Fig. 6. Current-voltage characteristics versus $10 \mathrm{keV}$ X-ray dose (517 $\left.\operatorname{rad}\left(\mathrm{SiO}_{2}\right) / \mathrm{s}\right)$ for $14 \mathrm{~nm}$ bulk nFinFETs in the linear region $\left(\mathrm{V}_{\mathrm{D}}=+50 \mathrm{mV}\right)$. ON bias during irradiation.

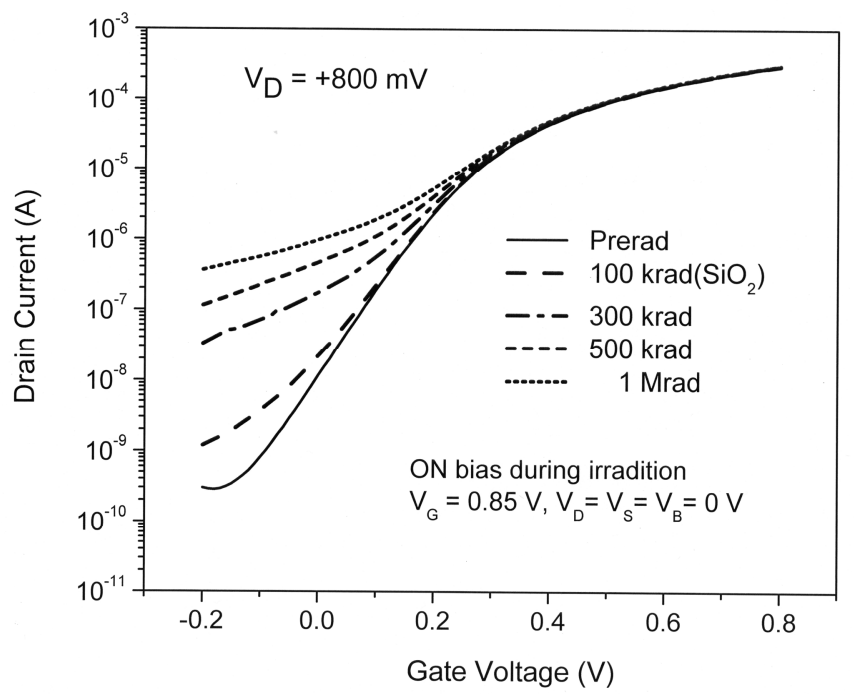

Fig. 7. Current-voltage characteristics versus $10 \mathrm{keV}$ X-ray dose (517 $\left.\operatorname{rad}\left(\mathrm{SiO}_{2}\right) / \mathrm{s}\right)$ for $14 \mathrm{~nm}$ bulk nFinFETs in saturation $\left(\mathrm{V}_{\mathrm{D}}=+800 \mathrm{mV}\right)$. ON bias during irradiation.

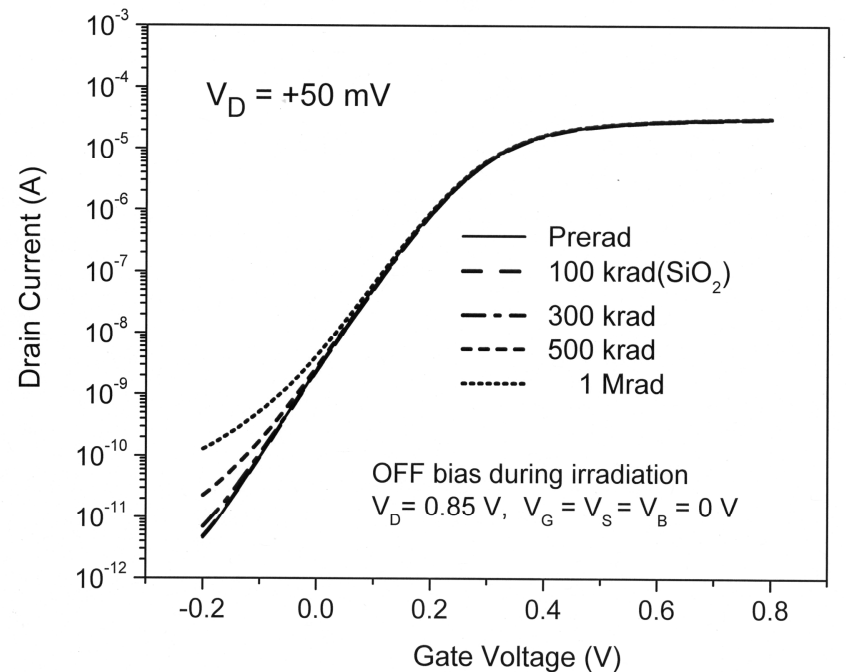

Fig. 8. Current-voltage characteristics versus $10 \mathrm{keV}$ X-ray dose (517 $\left.\operatorname{rad}\left(\mathrm{SiO}_{2}\right) / \mathrm{s}\right)$ for $14 \mathrm{~nm}$ bulk nFinFETs in the linear region $\left(\mathrm{V}_{\mathrm{D}}=+50 \mathrm{mV}\right)$. OFF bias during irradiation.

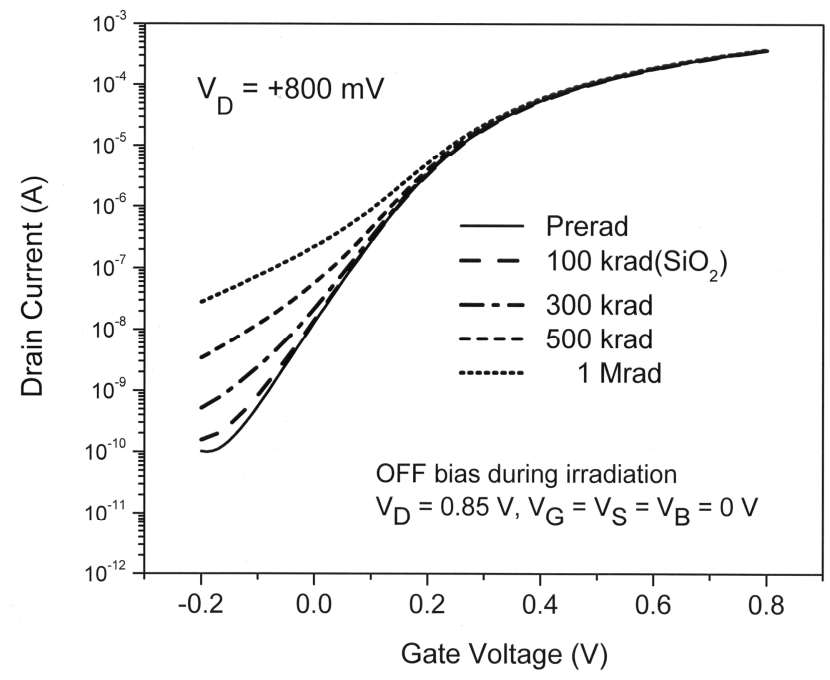

Fig. 9. Current-voltage characteristics versus $10 \mathrm{keV}$ X-ray dose (517 $\left.\operatorname{rad}\left(\mathrm{SiO}_{2}\right) / \mathrm{s}\right)$ for $14 \mathrm{~nm}$ bulk $\mathrm{nFinFETs}$ in saturation $\left(\mathrm{V}_{\mathrm{D}}=+800 \mathrm{mV}\right)$. OFF bias during irradiation.

As shown in Fig. 6 and Fig. 8 there is no significant change in threshold voltage (determined from the linear region) following irradiation for the two bias conditions, but large increases in off-state current as shown in Fig. 7 and Fig. 9 (saturation). Fig. 10 is a summary of off-state current as a function of X-ray dose for the bulk silicon FinFETS. ON bias is the worst case for off-state current increase. 


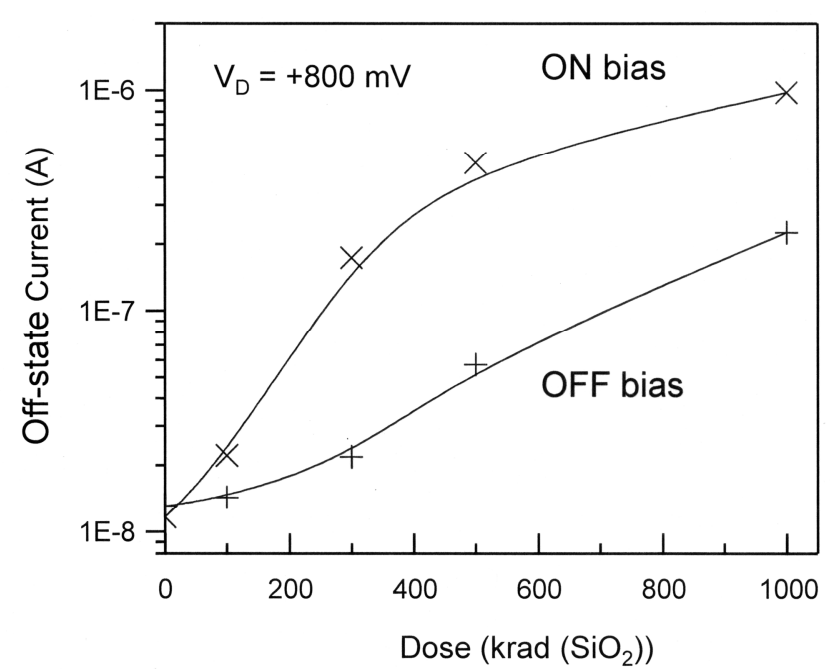

Fig. 10. $14 \mathrm{~nm}$ bulk FinFET off-state current increase following $10 \mathrm{keV} \mathrm{X-}$ ray irradiation $\left(517 \operatorname{rads}\left(\mathrm{SiO}_{2}\right) / \mathrm{s}\right)$ for $\mathrm{ON}$ and $\mathrm{OFF}$ bias during irradiation (saturation $\mathrm{V}_{\mathrm{D}}=+800 \mathrm{mV}$ ).

\section{Discussion Tid Results-FinfeTs}

The TID responses of bulk silicon and SOI FinFETs are significantly different in terms of radiation-induced threshold voltage shift and radiation-induced off-state current increase. Bulk silicon FinFET radiation tolerance is reduced due to an increase in off-state current, and SOI FinFET radiation tolerance is reduced due to threshold voltage shifts.

For SOI FinFETs, OFF bias during irradiation results in the largest threshold voltage increase. For the bulk silicon FinFETs, ON bias during irradiation results in the largest increase in off-state current and this occurs when the device is operated in saturation.

\section{TID Results-Soi UtbB Fets}

The use of fully depleted (FD) UTBB for scaling CMOS/SOI technology below $32 \mathrm{~nm}$ provides a number of major advancements over partially depleted (PD) CMOS/SOI: short-channel electrostatic control, reduced stage delay time, and reduced single event transients. As a planar technology, compared to 3D FinFET technology, UTBB also provides a way for backside threshold voltage control.

The UTBB nFETs were fabricated on SOI substrates with a top silicon thickness of $6 \mathrm{~nm}$ and a BOX thickness of 25 $\mathrm{nm}$. These nFETs have a channel length of $22 \mathrm{~nm}$ and channel width of 1.2 microns. The nFETS were irradiated using the $10 \mathrm{keV} X$-ray source in ON, OFF and PG bias. The results are shown in Fig. 11, Fig. 12 and Fig. 13 with a summary shown in Fig. 14.

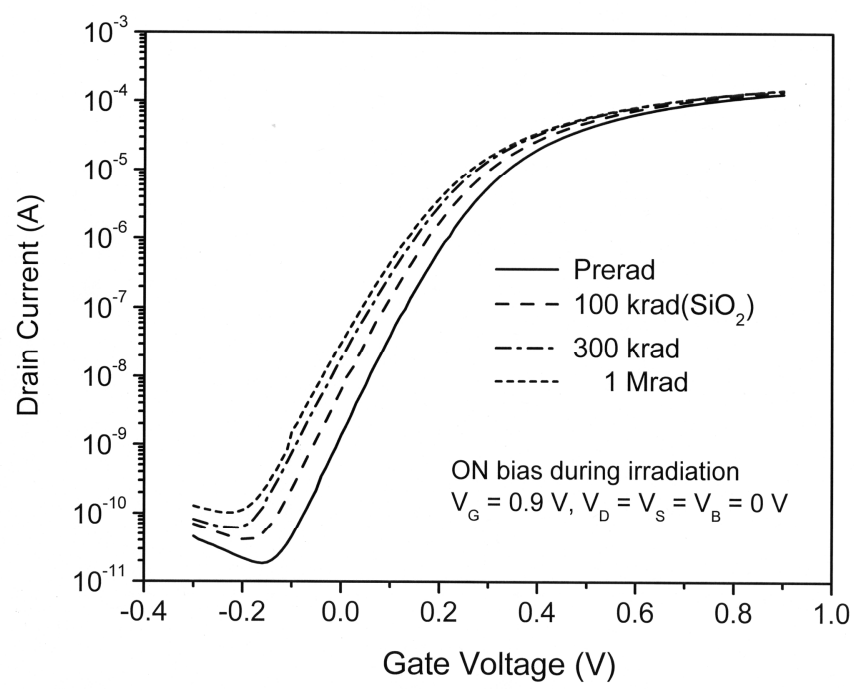

Fig. 11. Current-voltage characteristics versus $10 \mathrm{keV}$ X-ray dose $(517$ $\left.\operatorname{rad}\left(\mathrm{SiO}_{2}\right) / \mathrm{s}\right)$ for $14 \mathrm{~nm}$ SOI UTBB $\mathrm{nFETs}\left(\mathrm{V}_{\mathrm{D}}=+50 \mathrm{mV}\right)$. ON bias during irradiation.

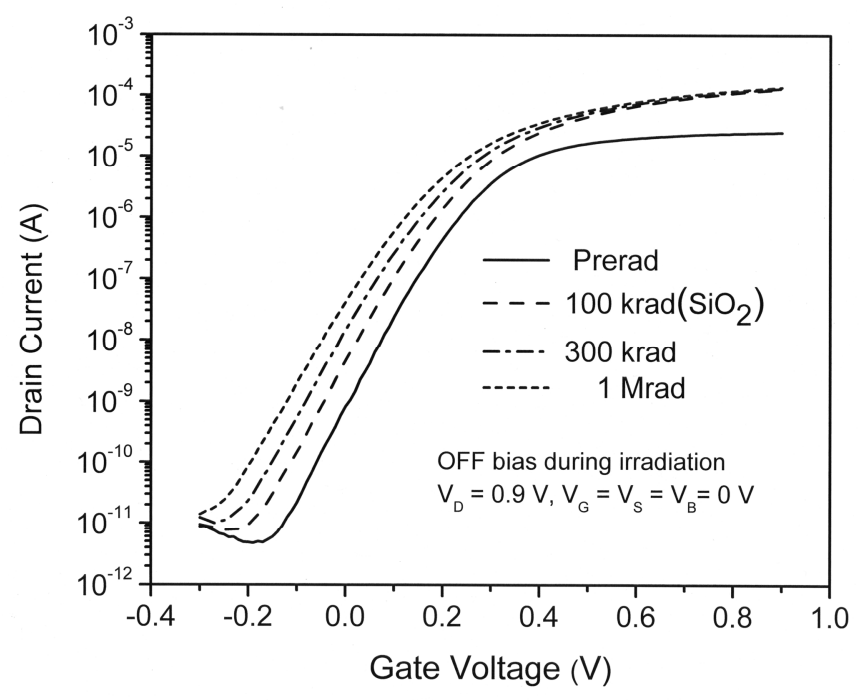

Fig. 12. Current-voltage characteristics versus $10 \mathrm{keV}$ X-ray dose (517 $\left.\operatorname{rad}\left(\mathrm{SiO}_{2}\right) / \mathrm{s}\right)$ for $14 \mathrm{~nm}$ SOI UTBB $\mathrm{nFETs}\left(\mathrm{V}_{\mathrm{D}}=+50 \mathrm{mV}\right)$. OFF bias during irradiation. 


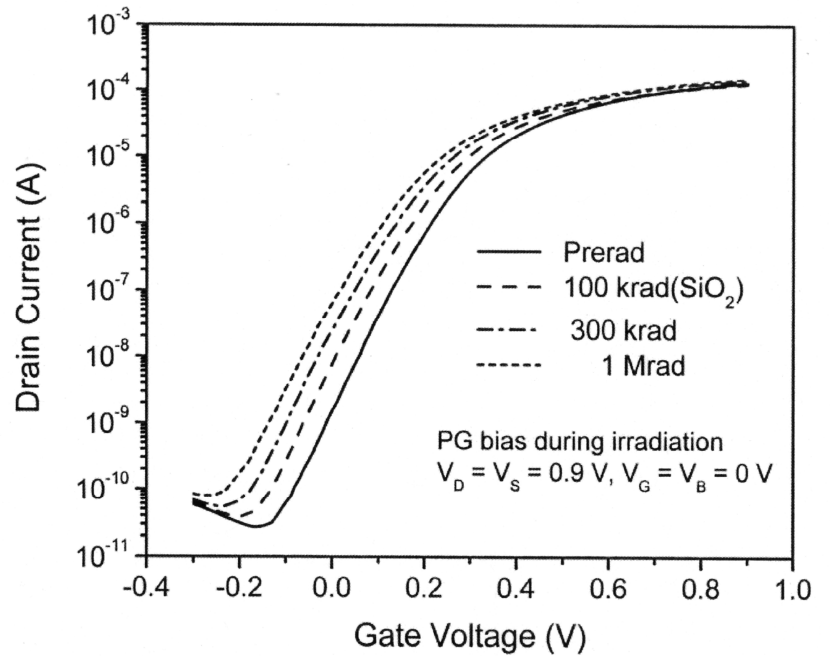

Fig. 13. Current-voltage characteristics versus $10 \mathrm{keV}$ X-ray dose (517 $\left.\operatorname{rad}\left(\mathrm{SiO}_{2}\right) / \mathrm{s}\right)$ for $14 \mathrm{~nm}$ SOI UTBB $\mathrm{nFETs}\left(\mathrm{V}_{\mathrm{D}}=+50 \mathrm{mV}\right)$. PG bias during irradiation.

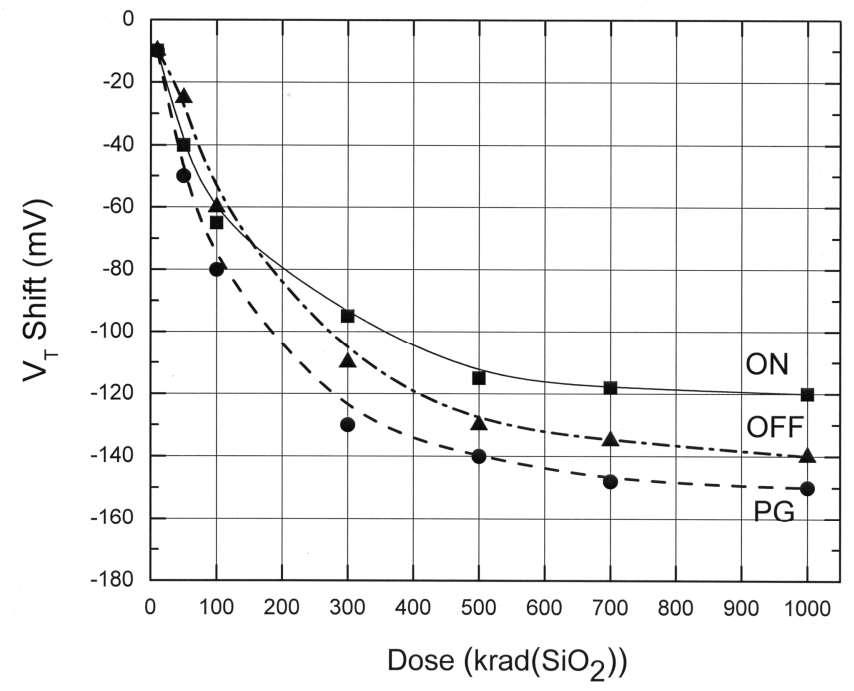

Fig. 14. Threshold voltage shifts for $14 \mathrm{~nm}$ SOI UTBB nFETs biased ON, OFF and $P G$ during $X$-ray irradiation $\left(\mathrm{V}_{\mathrm{D}}=+50 \mathrm{mV}\right)$.

The largest threshold voltage shifts for UTBB are observed for PG bias during irradiation. In this case a fringing field extends from the source and drain through the buried oxide to the channel. During irradiation this field results in holes, created in the buried oxide, being driven to the channel/box interface and being trapped there. This trapped charge is coupled to the top gate resulting in threshold voltage shifts.

The effect of charge coupling from the BOX to the top gate transistor for fully-depleted technology is calculated using the following equation [5]:

$\Delta \mathrm{V}_{\text {top gate }}=\mathrm{k} \Delta \mathrm{V}_{\text {back gate }}$

Voltage shift of top gate $=\mathrm{k}$ times voltage shift of back gate

Where the coupling factor $\mathrm{k}$

$\mathrm{k}=\left[\left(\mathrm{C}_{\mathrm{BOX}} \mathrm{C}_{\mathrm{S}) \mathrm{i}} /\left(\mathrm{C}_{\mathrm{BOX}}+\mathrm{C}_{\mathrm{Si}}\right)\right] / \mathrm{C}_{\text {top }}\right.$

$\mathrm{C}_{\mathrm{BOX}}=$ buried oxide capacitance $=\varepsilon_{\mathrm{o}} \varepsilon_{\mathrm{BOX}} / \mathrm{t}_{\mathrm{BOX}}$
$\mathrm{C}_{\mathrm{Si}}=$ silicon channel capacitance $=\varepsilon_{0} \varepsilon_{\mathrm{Si}} / \mathrm{t}_{\mathrm{Si}}$

$\mathrm{C}_{\text {top }}=$ top gate dielectric capacitance $=\varepsilon_{0} \varepsilon_{\text {top gate }} / \mathrm{t}_{\text {top gate }}$

$\varepsilon_{\mathrm{o}}=8.86 \times 10^{-14} \mathrm{~F} / \mathrm{cm}$

thickness of BOX ( $\left.\mathrm{t}_{\mathrm{BOX}}\right)=145 \mathrm{~nm}$ or $25 \mathrm{~nm}$

equivalent oxide thickness of top gate dielectric

$$
\left(\mathrm{t}_{\text {top gate }}\right)=2.8 \mathrm{~nm}
$$

thickness of silicon channel $\left(\mathrm{t}_{\mathrm{Si}}\right)=60 \mathrm{~nm}$

dielectric constant of $\mathrm{SiO}_{2} \mathrm{BOX}\left(\varepsilon_{\mathrm{BOX}}\right)=3.9$

dielectric constant of top gate equivalent oxide

$$
\left(\varepsilon_{\text {top gate }}\right)=3.9
$$

dielectric constant of silicon channel $\left(\varepsilon_{\mathrm{Si}}\right)=11.7$

The above equation was used to produce a plot of front gate threshold voltage shifts vs. back gate voltage shifts for two different BOX thicknesses. Fig. 15 shows the results from this calculation for BOX thickness values of $25 \mathrm{~nm}$ and $145 \mathrm{~nm}$ and measured results from nFETs with these thickness values.

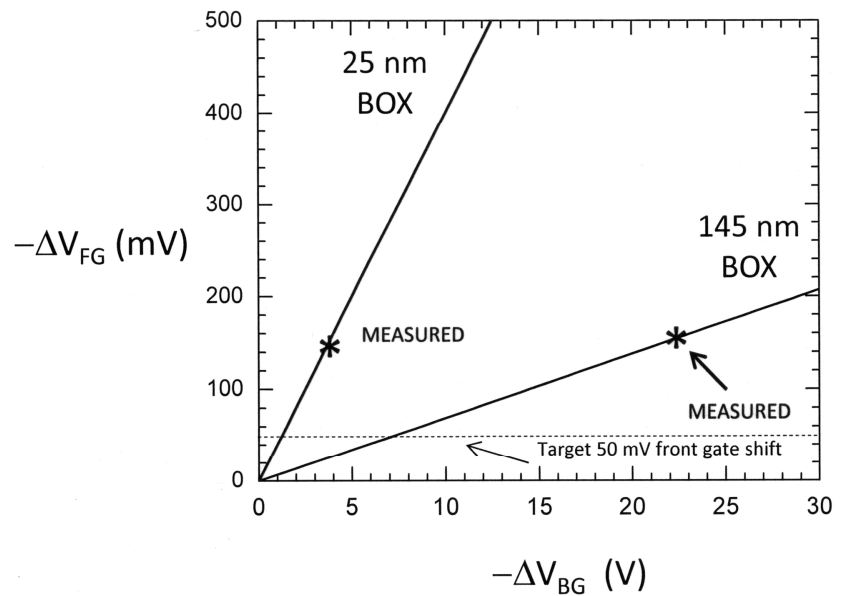

Fig. 15. Fully-depleted calculated charge coupling of front gate (FG) threshold voltage shifts to back gate (BG) threshold voltage shifts for two BOX thicknesses.

For nFETs built on $145 \mathrm{~nm}$ BOX, the top gate shift was $140 \mathrm{mV}$ and the back gate shift was $-22 \mathrm{~V}$, in good agreement with the calculated values shown in Fig. 15. For nFETs built on $25 \mathrm{~nm}$ BOX the front gate shift was $-150 \mathrm{mV}$ (Fig. 14) and the back gate shift was $-3 \mathrm{~V}$, again in good agreement with the calculated values. This is strong evidence that the top gate threshold voltage shifts result from coupled radiation-induced positive trapped charge in the BOX.

\section{SUMMARY}

TID vulnerability is found to increase when CMOS technology nodes scale below $32 \mathrm{~nm}$. Depending on design, radiation induced threshold voltage shifts from $-25 \mathrm{mV}$ to $50 \mathrm{mV}$ can be tolerated, and off-state current increases from $5 \mathrm{X}$ to $10 \mathrm{X}$ of prerad values can be tolerated [6]. Using these 
values, the results of the present work can be used in a very preliminary sense to define the radiation tolerance of the 14

$\mathrm{nm}$ technologies. For designs that can function with threshold voltage shifts of $-50 \mathrm{mV}$, the radiation tolerance of bulk silicon FinFETs is $200 \mathrm{krad}\left(\mathrm{SiO}_{2}\right)$, while the SOI FinFETs have a radiation tolerance of $300 \mathrm{krad}\left(\mathrm{SiO}_{2}\right)$. The UTBB devices have a radiation tolerance of $50 \mathrm{krad}\left(\mathrm{SiO}_{2}\right)$.

\section{REFERENCES}

[1] N. Rezzak, E. X. Zhang, M. L. Alles, R. D. Schrimpf, and H. L. Hughes, "Total-Ionizing-Dose Radiation Response of PartiallyDepleted SOI Devices," Proc. IEEE Int. SOI Conf., Oct. 2010.

[2] S. T. Liu, A. Hurst, H. L. Hughes, P. McMarr, J. Benedetto, and C. Capasso, "Total dose radiation response of a $45 \mathrm{~nm}$ SOI Technology," Proc. IEEE Int. SOI Conf., Oct. 2010.

[3] L. Palkuti, M. Alles and H. Hughes, "The Role of Radiation Effects in SOI Technology Development," Proc. IEEE SOI-3D Conf., Oct. 2014.

[4] M. L. Alles, H. L. Hughes, D. R. Ball, P. J. McMarr, R. D. Schrimpf, "Total-Ionizing-Dose Response of Narrow, Long Channel $45 \mathrm{~nm}$ PDSOI Transistors," IEEE Trans. Nucl. Sci., 61(6), 2945 (2014).

[5] W. C. Jenkins and S. T. Liu, "Radiation Response of Fully Depleted MOS Transistors Fabricated in SIMOX," IEEE Trans. Nucl. Sci., 41(6), 2317 (1994).

[6] B. Doris, IBM Research, private communication. 